\title{
Health, Aging and Quality of Life: An Evaluation of Experience in Family Health Unit through Popular Education
}

\author{
Cristina Katya Torres Teixeira Mendes¹, Fabia Barbosa de Andrade², \\ Danielle Nóbrega de Castro ${ }^{3}$, Maria do Socorro Feitosa Alves"4, \\ Gilson de Vasconcelos Torres ${ }^{5}$, Maria Adelaide Paredes Moreira ${ }^{6}$, Antonia Oliveira Silva ${ }^{7}$ \\ ${ }^{1}$ Nursing, Federal University of Rio Grande do Norte, Natal, Brazil \\ ${ }^{2}$ Department of Nursing, FACISA, Federal University of Rio Grande do Norte, Natal, Brazil \\ ${ }^{3}$ Municipal Health João Pessoa, Paraíba, Brazil \\ ${ }^{4}$ Department of Dentistry, Federal University of Rio Grande do Norte, Natal, Brazil \\ ${ }^{5}$ Department of Nursing, Federal University of Rio Grande do Norte, Natal, Brazil \\ ${ }^{6}$ Nursing, Federal University of Paraíba, João Pessoa, Brazil \\ ${ }^{7}$ Department of Public Health and Psychiatry, Federal University of Paraíba, João Pessoa, Brazil \\ Email: cristinakatya@bol.com.br, fabiabarbosabr@yahoo.com.br, daniellenobrega@gmail.com, alfa@ufrnet.br, \\ gilsonvtorres@hotmail.com,.jpadeliade@hotmail.com, alfaleda@hotmail.com
}

Received 5 June 2014; revised 22 July 2014; accepted 5 August 2014

Copyright (C) 2014 by authors and Scientific Research Publishing Inc.

This work is licensed under the Creative Commons Attribution International License (CC BY).

http://creativecommons.org/licenses/by/4.0/

(c) (i)

Open Access

\section{Abstract}

This study aims to assess the implementation of the Health, Aging and Quality of Life. The specific objectives were executed by conducting activities with the elderly through generative themes with an emphasis on health, aging and quality of life; evaluation of the experience of older people in Unity Family Health with Popular Education; analyzing the evolution of indicators of health and quality of life of elderly patients after two years and ascertaining the effectiveness of Popular Education in the elderly group in the Family Health Unit. This is an exploratory study approved by the Ethics and Research Committee UFPB/CCS, number 0598/08 held on Primary Health Care. The project consists of two lines of integrated activities: Group Active Ageing (GEA), which brings together seniors for addressing issues related to healthy aging and the Multidimensional Health Assessment and Quality of Life through the WHOQOL-BREF. The activities were built in fortnightly meetings from the dialogue where experiences are shared and collective needs. Thus, relevant topics were suggested for the group: guidelines on physical activity, nutrition, chronic disease prevention, self-esteem, among others, and group dynamics as body stretching, stretching exercises, respiratory, metabolic and relaxation. The observed results are the very satisfactions group, reported through testimonies and translated by the enthusiasm and diligence in participation. This project promoted a better bio-psycho-social development of the elderly, reinforcing its iden- 
tity by promoting and facilitating the expression of their potential positive and arousing them to a better future life prospects and community socialization feelings.

\title{
Keywords
}

\author{
Health, Aging, Quality of Life
}

\section{Introduction}

The aging population is one of the greatest triumphs of humanity and also one of our greatest challenges.

As we enter the twenty-first century, global aging will cause an increase in social and economic demands worldwide. However, people's "best age" is generally ignored in the feature; when in fact, it constitutes important resource for the structure of our societies [1].

Aging is a natural phenomenon of life of an individual, is a general, dynamic, progressive, slow and gradual process, which is affected contributes to a variety of genetic, biological, social, environmental, psychological and cultural.

Among the issues surrounding aging, exacerbated in exclusionary and unequal societies, health plays a strategic role for its strong impact on the quality of life for seniors and for being the target of social stigmas and prejudices played toward aging [2].

The theme of quality of life in recent years, has been treated in the most different ways, both in everyday language and in university. Health interest in this topic is relatively recent and stems from new paradigms that have influenced the policies and practices of the industry in recent decades [3], understanding that health and disease are part of the complex multifactorial process related to the economic, socio-cultural, life style and personal experiences, among others.

It is the function of health policies that help more people reach old age with the best health possible. The active and healthy aging is the major objective in this process. If we consider the health field as a broad becomes necessary a change in the current context toward the production of a social and cultural environment more favorable for the elderly, thereby including the quality of life.

Group work is a reality in the daily lives of the teams Primary Care/Family Health who developed thematic groups. Much of the staff working with the activities of groups considered that the elderly are the groups included hypertension and diabetes, which reinforces the treatment of aging as a disease, which is not true.

We highlight the role of socialization obtained in any group work, which alone can provide new perspectives for the elderly, as well as greater acceptance in society. It is necessary to further consideration of the health teams Primary Care/Family Health on group work, to be able to use it in a more reflective and effective way [2].

In place of apprehension health through disease, enrolled in biomedical normativity transposed to the classical approaches of Health Education, the practices targeted by the Popular Education incorporate the complexity of the health-disease-care, opening up the recognition of the economic, political, social, cultural and spiritual therein involved [4].

In Brazil, the prospect of a comprehensive action and critical approach of Health Education, committed to humanizing, equity and social justice, has been the line taken by professionals identified with the area that has been recognized as Popular Education in Health. It is an area that envolves many hues but converges trends on some theoretical and methodological principles whose roots are in the pedagogical concepts of the educator, a Brazilian intellectual world renowned of great relevance in the international debate on educational practices in health promotion [1].

Education is fertilized by the active involvement of learners through dialogue, sharing their knowledge and experiences of questioning about the contents mediated in teaching-learning process. The vertical practices in which sender and receiver polarize positions of knowledge and ignorance, respectively, are questioned on their potential for indoctrination and manipulation.

The questioning is to Paulo Freire, a fundamental goal in any endeavor of popular education and represents the possibility of awareness of reality from reflection on man's relations with the world and with others [4]. 
For the author, at the bottom, “(...) questioning is the reflection that someone has on a content, the result of an act, or the act itself, to act better, with others, in fact." [5] In health education, reflection and action are horizons that involve both subjects involved, and that are beyond the immediate and critical appropriation of behavioral norms dissociated from his problematic in the social context.

So the dialogue exercise is favored by dynamic work promoting the participation and AAG is going to be a space that enhances the interaction and critical reflection from the involvement of all the construction and the collective from the unique history and thought of each. Participatory processes are thought to further promote the participation of individuals in society, raised by the joint reflection of the problems experienced and the awareness of the need to tread ways of overcoming, of collectively assume the construction of citizenship and breaking the logic denial of rights inscribed in reality and reflected in the health-illness care.

In summary, the Project Health, Aging and Life Quality driven Popular Education may [6]:

“(...) A continuous and participatory process, which takes place from the dialogue, the exchange of knowledge, experiences and feelings, and the construction of new knowledge and practices, aimed at understanding the realities and constraints of the health/illness/health. It is hoped that this knowledge, enable, increasingly, critical, creative and sensitive participation in the various sectors of society in pursuit of improved quality of life."

And from the point of view of change in health practices, actions are guided by the Popular Education [3], extending the tool in health care, contributing to comprehensive care, humanization of services and commitment to confronting more global health problems of the population.

This experiment aimed at contributing to the promotion of healthy aging, thematic relevance in the context of health policy worldwide, taken as a guideline of National Health Policy for the Elderly [3].

\section{Methodology}

Developed an evaluation research for the purpose of implementing the Project Health, Aging and Quality of Life in exploratory. The specific objectives were executed by conducting activities with the elderly through generative themes with an emphasis on health, aging and quality of life; evaluation of the experience of older people in the Family Health Unit I Grotão with the Popular Education; analyzing the evolution of indicators health and quality of life of elderly patients after two years and ascertaining the effectiveness of Popular Education in the elderly group at the Family health Unit I.

Search 48 elderly participants, 35 were female and 13 male of the Elderly group of Family Health Unit IGrotão, in the district of João Pessoa-Paraíba.

- The group formed and began its activities in the month of August 2009. The meetings were held two times per week, lasting 1 hour in Unit Strategic Family Health Unit I, in the community of Grotão.

- The group was assessed on the first and last meeting, in order to compare the results. Therefore, elaborate an assessment tool based on the popular practice of education (Appendix I). And we also applied the Multidimensional Health Assessment and Quality of Life (WHOQOL-OLD and WHOQOL-BREF).

\section{Discussion and Analysis of Results}

It is known that the Primary Attention is characterized by a set of health actions, both individually and collectively, covering the promotion and protection of health, disease prevention, diagnosis, treatment, rehabilitation and maintenance of health. Guided by the principles of universality, accessibility and coordination of care, bond and continuity, comprehensiveness, accountability, humanization, equity and social participation [2].

The data presented in Table 1 show that Group Dynamics (GD) was the most important issue. Aging with $13.5 \%$ for the informal discussion (DI) was about $13.0 \%$ with diabetes and Exhibition and Debate (ED) issues related to osteo-articular diseases with $28.6 \%$. And the topics discussed were little to DG Depression was $1.7 \%$ for DI was Food and Depression with 4.3 and ED were the Hypertension and Diabetes themes with 4.8\% each.

The new ways of experiencing the aging process from this experience this detailed in Table 2, the testimonies collected showed that most of the elderly showed a positive change in the way we perceive and deal with old age with $24.6 \%$.

The activities of this project were carried out in the community Grotão, located on the outskirts of João 
Table 1. Educational approaches used in GES according to themes—2009 and 2010.

\begin{tabular}{|c|c|c|c|c|c|c|}
\hline \multirow{3}{*}{ Issues } & \multicolumn{6}{|c|}{2009 and 2010} \\
\hline & \multicolumn{2}{|c|}{ Group dynamics } & \multicolumn{2}{|c|}{ Informal debate } & \multicolumn{2}{|c|}{ Exhibition and debate } \\
\hline & No. & $\%$ & No. & $\%$ & No. & $\%$ \\
\hline Aging & 10 & 13.5 & 06 & 8.7 & - & - \\
\hline Hypertension & 05 & 11.8 & 03 & 8.7 & 02 & 4.8 \\
\hline Family & 08 & 10.2 & 06 & 6.8 & - & - \\
\hline Food & 02 & 8.5 & 01 & 4.3 & 04 & 19.0 \\
\hline Diabetes & 01 & 6.8 & 02 & 13.0 & 01 & 4.8 \\
\hline Physical activity & 05 & 5.1 & 02 & 8.7 & 03 & 14.3 \\
\hline Osteo-articular problems & 06 & 3.4 & 02 & 8.7 & 08 & 28.6 \\
\hline Depression & 01 & 1.7 & 01 & 4.3 & 06 & 23.8 \\
\hline Social rights of the Elderly & 04 & 6.8 & 02 & 8.7 & - & - \\
\hline Total & 46 & 100 & 25 & 100 & 24 & 100 \\
\hline
\end{tabular}

Table 2. New ways of experiencing the aging process from the experience of the GES, 2009 and 2002.

\begin{tabular}{|c|c|c|}
\hline Aspects mentioned in the depositions & No. & $\%$ \\
\hline Positive change in the way we perceive and deal with old age & 12 & 24.6 \\
\hline New ways of acting and awareness to self-care & 09 & 17.5 \\
\hline Improved self-esteem/attitude to life & 08 & 15.8 \\
\hline Incentive and opportunity to enter into new activities & 07 & 14.0 \\
\hline Personal growth by sharing problems and experiences of other & 04 & 8.8 \\
\hline Reinforcing the positive stance already adopted as the aging & 04 & 8.8 \\
\hline
\end{tabular}

Pessoa-PB. In Grotão, it will act in conjunction with Family Health Teams deployed there and the population enrolled in it.

The public to whom the activities included in this project were for people over 65, who are independent and have preserved cognitive memory. To this public were intended activities of necessary assistance and health education for the prevention of disease and maintenance of health through work with groups and collective actions directed at seniors.

The project Health, Aging and Quality of Life had two perspectives of action, a didactic-pedagogic perspective on learning that his actions led to the participants, and a perspective of social commitment, referring to actions performed with the residents of the communities where the same acts.

Regarding the didactic-pedagogic perspective, it emphasizes the relevance of this experience towards a change in the conception of health and professional performance. Evaluations conducted during project activities will highlight the experience that gives all members, broadening their understanding of the human disease process, forms of professional intervention and the role of health professional before collectives.

This project followed the families of the elderly, knowing how they face health problems, the local epidemiological context, performing actions on health education in a dialogue between scientific and popular knowledge. Right now, the performance of the popular educator takes on a broader scale, linked to the role of a health agent, establishing links with residents and community organization, seeking to contribute to the empowerment of these people. It acts, therefore, from the viewpoint of health promotion, understood as a process of training the population to improve their health and exercise greater control over the same, according to the World Health Organization (WHO). 
The project consists of two lines of action included: Active Aging Group (AAG), which brings together seniors for addressing issues related to healthy aging and the Multidimensional Health Assessment and Quality of Life through the WHOQOL-BREF, research tools developed WHO and educational and preventive action at the individual level, applied parallel to the work of the groups.

The Popular Education is a major differentiator for the participants of the Health, Aging and Quality of Life, because this study sought to enhance the knowledge and popular practices, seeking to establish a dialogical relationship with the actors with whom we dialogue, as well as contribute with the strengthening of these subjects. The Popular Education also influenced how project activities are managed, providing that all persons involved in this process were the protagonists, acting in the planning, execution and evaluation. And thus favoring the welfare of the elderly, through a process that stimulates thinking about the relationship body/life, toward integrating individual and collective making that involves health.

This experiment aimed at contributing to the promotion of healthy aging, thematic relevance in the context of health policy at the global level, taken as a guideline of National Health Policy for the Elderly in Brazil [7].

The project developed an educational and informative about aging instructing not only the concepts of selfcare, but also surfacing feelings, awakening values of social integration and strengthening the identity of the individual. The activities were built in fortnightly meetings from the dialogue where they shared experiences and collective needs. Thus, relevant topics were suggested as guidelines on physical activity, nutrition, chronic disease prevention, self-esteem, among others, as well as dynamic stretching body, stretching exercises, respiratory, metabolic and relaxation. He was part of the activities also, the use of artistic media, entertainment and experiences of Biodanza for integration and socialization.

The family health team could improve adherence to treatment of hypertensive and diabetic patients and patients with better approximation can share their anguish at being despised by families who just want to enjoy retirement and tension in days of shootout between police and traffickers existing that community. The elderly reported that constantly assiduity with the project began to experience the aging process in a more natural.

\section{Conclusion}

This project has promoted a large bio-psycho-social development elderly, reinforcing its identity by promoting and facilitating the expression of their potential positive feelings and awakening them to a better quality of life. This is due to the fact that this is a dialogue-based education, proposing the exchange of scientific and popular knowledge, where teaching and learning involves all stakeholders, generating motivation in the context of a commitment to health in the community. The group has established a policy on FHS (Family Health Strategy) and a culture of rights of the elderly, with the goal of promoting the destruction processes of social exclusion of this population, as well as building a prevention intervention that articulates the limitations of aging, health promotion and education. The Popular Education is a methodology that transforms the critical opinion of commitment to social reality and overall health contributes greatly to important changes and construe a more practical and fairer for the population health.

\section{References}

[1] Assis, M. (2004) Health Promotion and Aging: Evaluation of an Experience at the Clinic of the Center for Elderly Care UnATI/UERJ. Doctoral Thesis, National School of Public Health, Rio de Janeiro.

[2] Brazil. Ministry of Health (2005) Active Aging: A Policy of Health/World Health Organization. Translation Suzana Gontijo. Pan American Health Organization, Brasilia.

[3] Vasconcelos, E.M. (1998) Popular Education as a Tool for Reorientation of the Control Strategies of Infectious and Parasitic Diseases. Journal of Public Health, 14, 39-58.

[4] Freire, P. (1982) Extension or Communication. 6th Edition, Trad. Rosisca Darcy de Oliveira. Continuum, Rio de Janeiro.

[5] Freire, Z.P. (1998) Pedagogy of Autonomy. Lessons in Educational Practice. 7th Edition, Continuum, New York.

[6] Figueiró, A.C. (1998) Popular Education in Health Why Not? Health Education Institution State Department of Health, Recife Pernambuco, Brazil.

[7] Brazil. Ministry of Health (2006) Aging and Health of the Elderly. Notebooks Primary Care, Brasilia. 
Scientific Research Publishing (SCIRP) is one of the largest Open Access journal publishers. It is currently publishing more than 200 open access, online, peer-reviewed journals covering a wide range of academic disciplines. SCIRP serves the worldwide academic communities and contributes to the progress and application of science with its publication.

Other selected journals from SCIRP are listed as below. Submit your manuscript to us via either submit@scirp.org or Online Submission Portal.
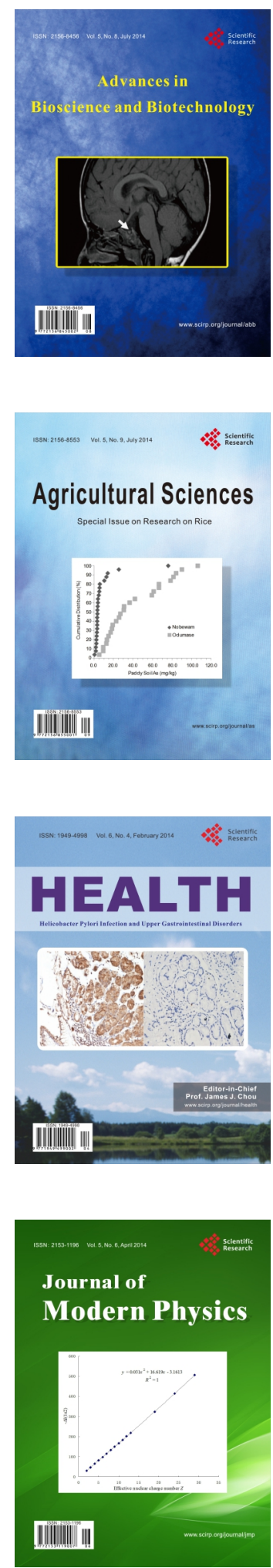
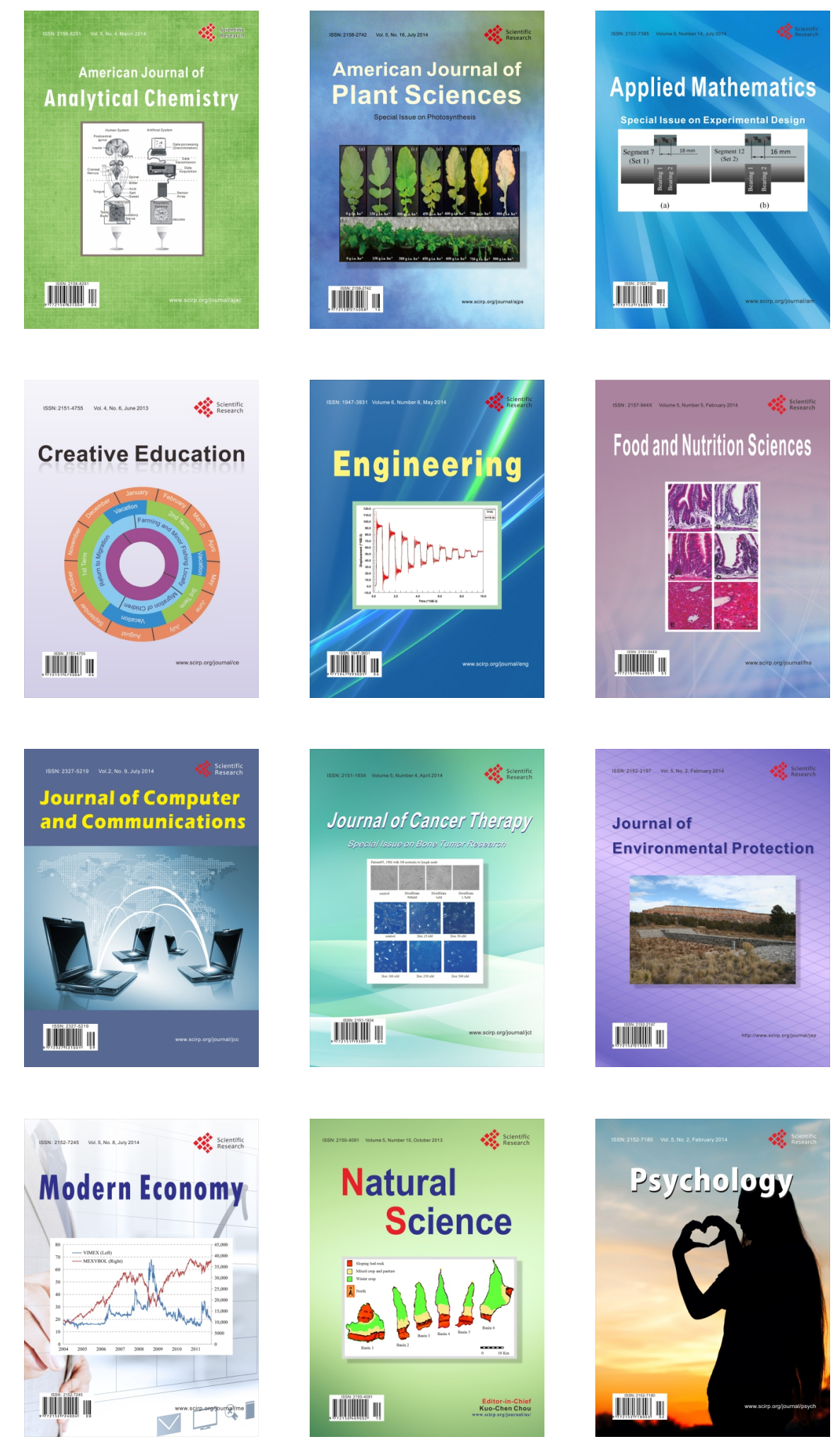